\title{
Ovarian Neoplasm: Diagnostic Accuracy of Ultrasound Guided Fine Needle Aspiration Cytology with Histopathological Correlation
}

\author{
${ }^{1 .}$ Dr. Neetu Agarwal, ${ }^{2}$ Dr. Shiwani Garg, ${ }^{3}$ Dr. Neeru Aggarwal, \\ ${ }^{4}$ Dr. P. M. Santwani, \\ ${ }^{1,2}$ Resident, M.P.Shah Medical college, Jamnagar, Gujarat \\ ${ }^{3}$ Associate professor, M.P.Shah Medical college, Jamnagar, Gujarat \\ ${ }^{4}$ Professor and Head of the department, M.P.Shah Medical college, Jamnagar, Gujarat
}

\begin{abstract}
:
Background: Ovarian lesions are one of the most frequent lesions in women . The pre-operative diagnosis relies mainly on clinical and radiological findings while post-operative diagnosis is made by histo-pathological examination. With the advent of accurate imaging techniques like USG and CT scan, guided FNAC can prove to be an efficient diagnostic modality for ovarian neoplasm.

Aims \& Objectives: To evaluate the utility and accuracy of cytological diagnosis in ovarian lesions either nonneoplastic or neoplastic.

Material and Methods: A retrospective study was carried out over a period of 3.5 years. Total 125 cases were reported in cytology during this period. Diagnosis was established by FNAC performed under image guidance and confirmed by Histo-pathological examination. Cytology smears were stained by Pap and H\&E stain. Histology slides were stained with $H \& E$ stain.

Result: Of the total 125 cases, cytological diagnosis was offered in 110 cases of which 17 were non-neoplastic, 50 benign and 43 malignant. Cytological correlation with histopathological specimens was possible in 69 cases only. Concordant diagnosis was achieved in 63 cases while 6 were discordant. Sensitivity and specificity of cytological diagnosis were $77.2 \%$ and $97.9 \%$ respectively.

Conclusion: Guided FNAC for ovarian lesions is a relatively quick, easy and patient friendly procedure with fair diagnostic accuracy and minimal patient mortality. Cytological diagnosis can be used as a preoperative diagnosis for management of patient. Histopathology remains the gold standard procedure.
\end{abstract}

Key words: ovarian lesions, cyto-histopathological correlation, cytology, histopathology.

\section{Introduction}

Ovaries are paired pelvic female reproductive organ, frequently encountered by neoplastic lesions either benign or malignant. Ovarian cancers account for about $6 \%$ of all cancers in females. ${ }^{1}$

The clinico-pathological evaluation of ovarian masses is a challenging field. Difficulty in gaining access to the tumor site is itself a major obstacle and the wide spectrum of lesions presents a difficult picture to the pathologist. Unlike the cervix and uterus, ovaries are not clinically accessible, with only a few biochemical or immunological diagnostic techniques available to diagnose any suspected pathology. ${ }^{2}$ Fine needle aspiration cytology (FNAC) under ultrasonography (USG) or CT guidance can be regarded as the investigation of choice for diagnosis of abdominal masses in the early stages of disease. ${ }^{3}$ It can help in typing of uterine adnexal tumors, thus avoiding unnecessary surgical intervention. ${ }^{4}$ Geier and Strecker ${ }^{5}$ have suggested that FNAC should be used for (1) recurrent and metastatic tumors, (2) suspected benign ovarian cysts and (3) when the patient's condition is unsuitable for laparotomy. Despite the obvious advantages, the frequent use of image-guided FNAC for routine investigation and diagnosis of ovarian neoplasm is a controversial field and has been the subject of much debate.

This study was undertaken to assess the diagnostic accuracy of ultrasound guided FNAC as well as to evaluate the role of cytology as a rapid and cost-effective means of diagnosing ovarian tumors.

\section{Material and Methods}

This study has included 125 cases reported in cytology section of the department of pathology, Shri M. P. Shah Medical College, Jamnagar, Gujarat over a period of 3.5 years from January 2010 to May 2013.These patients presented in the outpatient section of the Department of Obstetrics and Gynaecology and were subsequently found to have an ovarian mass on clinical and radiological evaluation. After clinical workup, the patients were subjected to abdominal/pelvic USG-guided FNAC. The mass was localized and aspiration performed using a 22-to 23-gauge spinal needle attached to a $10 \mathrm{ml}$ syringe. Several passes were made when the 
needle was visualized within the lesion. Smears were fixed in methanol and stained with papanicolaou and H\&E stain. In cases where fluid was aspirated, cytospin preparation was also made.

Smears were evaluated for cellularity, arrangement of cells, type of Epithelial cells, foamy /hemosiderin laden macrophages, calcified or necrotic material and proteinaceous, granular, greasy or mucoid background.

Routine histology techniques were followed for histopathology specimens. Sections were stained with H\&E stain.

Ovarian lesions were classified according to WHO classification.

\section{Results}

Out of the total 125 cases where USG guided FNAC was performed, cytological diagnosis was rendered in 110 cases, while 15 cases were inconclusive due to inadequate sampling. Out of 110 cases where cytological diagnosis were given, $17(15.5 \%)$ cases were non-neoplastic ,50 (45.5\%) cases benign neoplastic and the rest $43(39 \%)$ cases labelled as malignant (fig.1)

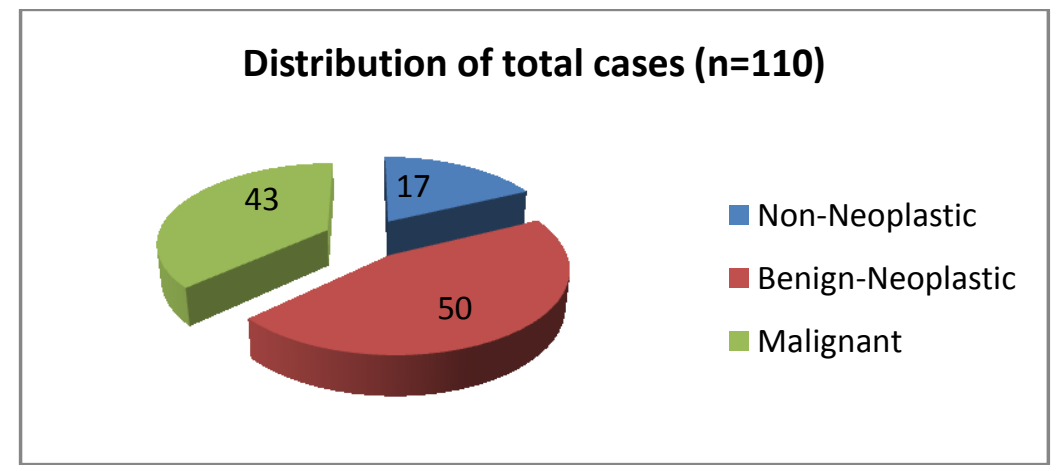

Distribution of total cases based on cytological diagnosis (fig.1) (Table -1).

Out of 17 non- neoplastic lesions, 10 were follicular cyst, 5 corpus luteal cyst and 2 endometriosis

Among the 50 benign neoplastic tumors, 26 (52\%) were serous cystadenoma, $16(32 \%)$ were mucinous cystadenoma.Rest were 5 cases of benign cystic teratoma, 2 of thecoma- fibroma, 1 of Brenner tumor ( Table-1).

Of the 43 malignant tumors, serous cystadenocarcinoma accounted for 25 (58.2\%) cases, mucinous cystadenocarcinoma for $10(23.2 \%)$ cases, granulosa cell tumor for 3 cases, metastatic tumor for 4 cases and endometrioid carcinoma for 1 (table-1).

Table 1 Cytological and Histopathological Correlation $(n=110)$

\begin{tabular}{|c|c|c|c|c|}
\hline Tumors & $\begin{array}{l}\text { Cytological } \\
\text { Diagnosis }\end{array}$ & $\begin{array}{l}\text { Histopathological } \\
\text { Diagnosis }\end{array}$ & Concordant & Discordant \\
\hline $\begin{array}{l}\text { Non neoplastic lesion } \\
\text { 1.Follicular cyst } \\
\text { 2.Corpus luteal Cyst } \\
\text { 3.Endometriosis } \\
\end{array}$ & $\begin{array}{c}10 \\
5 \\
2\end{array}$ & $\begin{array}{l}9 \\
5 \\
2\end{array}$ & $\begin{array}{l}9 \\
5 \\
2\end{array}$ & $\begin{array}{l}- \\
- \\
-\end{array}$ \\
\hline $\begin{array}{l}\text { Benign } \\
\text { 1.Serous cystadenoma } \\
\text { 2.Mucinous } \\
\text { Cystadenoma } \\
\text { 3.Benign cystic } \\
\text { Teratoma } \\
\text { 4.Thecoma-fibroma } \\
\text { 5. Brenner tumor }\end{array}$ & $\begin{array}{r}26 \\
16 \\
5 \\
2 \\
1\end{array}$ & $\begin{array}{l}17 \\
13 \\
4 \\
1 \\
-\end{array}$ & $\begin{array}{l}13 \\
12 \\
4 \\
1 \\
-\end{array}$ & $\begin{array}{l}4 \\
1 \\
- \\
- \\
-\end{array}$ \\
\hline $\begin{array}{l}\text { Malignant } \\
\text { 1.Serous } \\
\text { Cystadenocarcinoma } \\
\text { 2.Mucinous } \\
\text { Cystadenocarcinoma } \\
\text { 3. Granulosa cell tumor } \\
\text { 4.Metastatic tumor } \\
\text { 5.Endometrioid } \\
\text { Carcinoma } \\
\end{array}$ & $\begin{array}{l}25 \\
10 \\
3 \\
4 \\
1 \\
\end{array}$ & $\begin{array}{l}10 \\
4 \\
1 \\
2 \\
1 \\
\end{array}$ & $\begin{array}{l}9 \\
4 \\
1 \\
2 \\
1 \\
1\end{array}$ & $\begin{array}{l}1 \\
- \\
- \\
- \\
-\end{array}$ \\
\hline Total cases & 110 & 69 & 63 & 6 \\
\hline
\end{tabular}


Among the total 110 cases, most common diagnosis was serous cystadenoma (23.6\%), followed by serous cystadenocarcinoma (22.7\%), followed by mucinous cystadenoma (14.5\%) .

Cyto-Histology correlation was possible only in 69 cases as many benign tumors were not operated and many malignant tumors were referred to higher centres. Cytological diagnosis was concordant in 63 cases. Discordant diagnosis was obtained in 6 cases (Table-1).

\section{Discussion}

In this study majority of the tumors belonged to the age group 41-50 years (25.3\%), followed by 21-30 years $(20 \%)$, followed by $31-40(17.9 \%) .83 .3 \%$ of benign tumours were below the age of 50 years. $80.0 \%$ of the malignant tumors presented at or above the age of 50 years. Minimum age of presentation recorded was 17 years with a diagnosis of benign cystic teratoma. Minimum age for malignant tumor was 35 years with a diagnosis of serous cystadenocarcinoma.

The aspirate from follicular cysts consisted of granulosa cells with round nuclei and scanty cytoplasm against a bloody background, as also reported by Nunez et al. ${ }^{6}$

The aspirate from luteal cysts comprised of large round cells with abundant foamy or granular eosinophilic cytoplasm and ill-defined cell borders with small, vesicular nuclei, similar to the observation of Moran et al. ${ }^{7}$ and Ganjei et al. ${ }^{8}$

Smears of endometriotic cysts showed hemosiderin-laden macrophages against a background of hemolysed blood.

Smears from serous cystadenoma revealed loose aggregates of benign epithelial cells with uniform round nuclei, consistent with Ramzy et al. ${ }^{9}[$ fig.2]

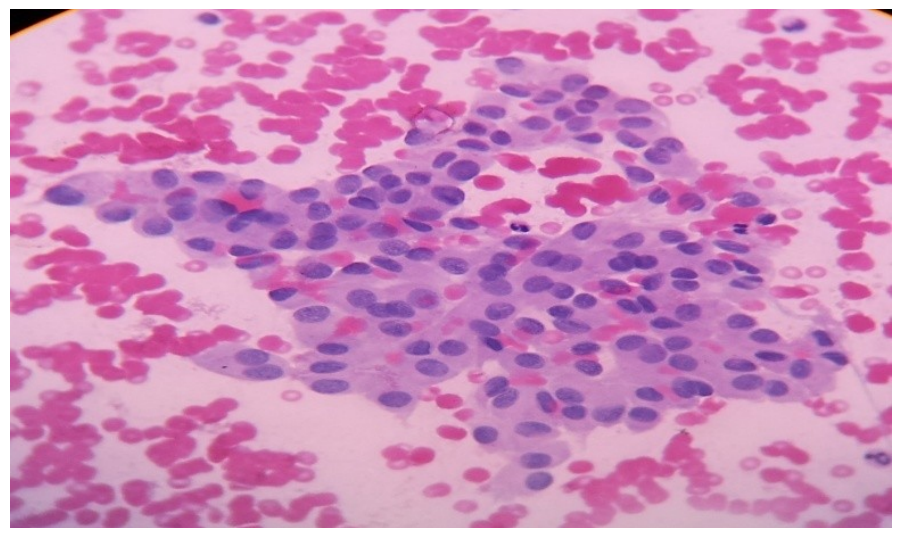

Fig.2 smear from Serous Cystadenoma (HE stain, 400X)

In cases of mucinous cystadenoma cytology showed groups of tall columnar cells with basal nuclei and clear cytoplasm.

Aspirate of benign cystic teratoma showed keratinized sheets and/or anucleate squames against a thick greasy background similar to the findings of Orell et al. ${ }^{10}$

Aspirate of thecoma fibroma showed moderate cellularity comprising of oval to spindle cells with scanty cytoplasm, finely granular chromatin and inconspicuous nucleoli, similar to the findings of Yang et al. ${ }^{11}$

In serous cystadenocarcinoma, on aspiration turbid fluid was obtained which showed papillary aggregates of columnar cells with hyperchromatic nuclei and high nucleo-cytoplasmic ratio. [fig.3]

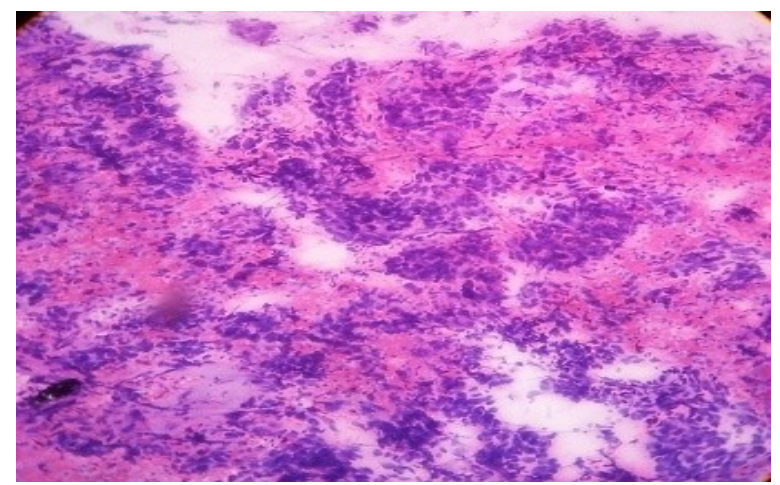

Fig. 3 smear from Serous Cystadenocarcinoma [HE stain, 100X] 
Sheets and clusters of neoplastic coloumnar cells with prominent vacuolization of cytoplasm forming signet ring cells were seen in mucinous cystadenocarcinoma smears.[fig.4]

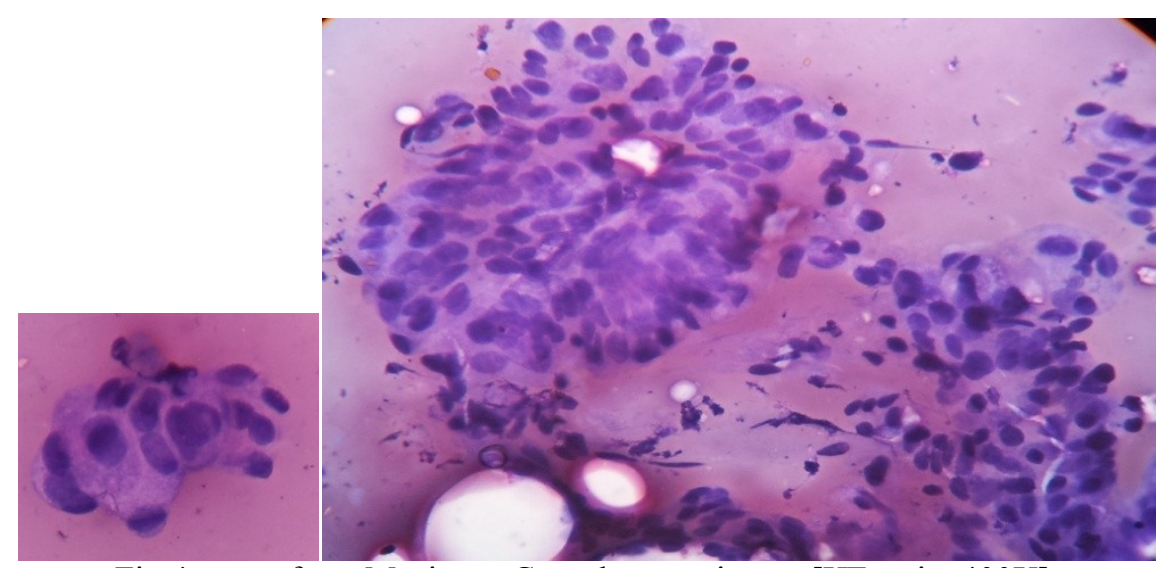

Fig.4 smear from Mucinous Cystadenocarcinoma [HE stain, 400X]

In cases of granulosa cell tumor cytology showed clusters of medium-sized cells with round to ovoid monomorphic nuclei and finely granular chromatin. Nuclear grooves were present in some but not all the cells, similar to Ehya et al. ${ }^{12}$

Of the 4 cases reported as serous cystadenoma on FNAC, 2 of them proved to be borderline serous cystadenoma, 1 serous cystadenocarcinoma and 1 was diagnosed as granulose cell tumor on histology. 1 case was diagnosed as mucinous cystadenoma on cytology but labeled as mucinous cystadenocarcinoma on histology. In 1 case a diagnosis of serous cystadenocarcinoma was given on FNAC but histology proved it to be a serous cystadenoma.

Several factors are responsible for discordant diagnosis obtained in 6 of our cases. First, most of the ovarian lesion were cystic, on FNAC fluid was aspirated which had an inadequate number of cells and also showed secondary degenerative changes. Second, malignant cells may not be equally distributed in ovary and the area aspirated may not be representative of the lesion as in 1 case of serous cystadenocarcinoma and 1 of mucinous cystadenocarcinoma diagnosed as their benign counterparts.

Borderline tumors were difficult to diagnose on cytological examination ,so were misdiagnosed as serous cystadenoma in 2 cases. This category of ovarian neoplasm constitutes a grey zone. A high index of suspicion and careful examination of nuclear features is therefore essential.

1 case of granulosa cell tumor misdiagnosed as serous cystadenoma due to the presence of acinar arrangement of cells with uniform nuclei.

1 case of serous cystadenoma was incorrectly labeled as serous cystadenocarcinoma due to presence of small cluster of cells with overlapping of nuclei giving the impression of multilayering.

A concordant cyto-histopathology correlation was observed in $91.3 \%$ of cases. The sensitivity and specificity of $77.2 \%$ \& $97.9 \%$ respectively in our study is in concordance with other researchers viz. Nazoora set $\mathrm{al}^{13}(79.2 \% \& 90,6 \%)$, Ganjei et $\mathrm{al}^{8}(94.2 \% \& 75 \%)$ and Roy et $\mathrm{al}^{14}(91.4 \% \& 100 \%)$.

\section{Conclusion}

(1) Guided aspiration cytology is a relatively quick, easier and patient friendly procedure with minimal morbidity, particularly in young women with functional cyst to avoid unnecessary surgery and to retain reproductive capacity.

(2) False negative results of FNAC in ovarian lesions are usually due to scanty cellularity and secondary degenerative changes of fluid.

(3) Borderline tumors cannot be diagnosed confidently by cytology alone.

(4) Cytological diagnosis should be used as a preoperative diagnosis to guide the management of patient; however histopathology remains the gold standard procedure.

\section{References}

[1]. Russel P, Bannatyne P: Surgical pathology of the ovaries, Edinburg, Churchill Livingstone. 1989.

[2]. Hajdu S, Melamed MR. Limitations of aspiration cytology in the diagnosis of primary neoplasms. Acta cytol.1984;28:337-45.

[3]. Ahmad SS, Akhtar K, Akhtar S, Abrari A, Nasir A, Khalid M, et al. Ultrasound guided fine needle aspiration biopsy of abdominal masses. JK Science 2006;8:200-4.

[4]. Ferran A, Gallardo J, Padilla C, Combalia N, Mellado F, Rey M. Fine needle aspiration of benign uterine adnexal lesions. Acta Cytol 1995;39:291.

[5]. Geier GR, Strecker JR. Aspiration Cytology and E2 content in ovarian tumors. Acta Cytol 1981; 25: 400-6. 
[6]. Nunez C, Diaz JI. Ovarian follicular cysts: A potential source of false - positive diagnoses in ovarian cytology. Diagn Cytopathol. 1992;8:532-7.

[7]. Moran O, Menczer J, Gijlad BB, Lipitz S, Goor E. Cytologic examination of ovarian cyst fluid for the distinction between benign and malignant tumors. Obstet Gynecol. 1993;82:444-6.

[8]. Ganjei P, Dickinson B, Harrison TA, Nassiri M, Lu Y. Aspiration cytology of neoplastic and non-neoplasic ovarian cysts: Is it accurate? Int J Pathol. 1996;15:94-101

[9]. Ramzy I, Martinez SC, Schantz HD. Ovarian cysts and masses: Diagnosis using fine needle aspirations. Cancer Detect Prev. 1981;4:493-502.

[10]. Orell SR, Sterrett GF, Walters MN, Whitaker D. In: Fine needle aspiration cytology. 3rd ed. Edinburgh London: Churchill Livingstone; 1999. Male and female genital organs; pp. 362-3.

[11]. Yang GC, Mesia AF. FNAC of fibrothecoma of the ovary. Diagn Cytopathol. 1999;22:284-6.

[12]. Ehya H, Lang WR. Cytology of granulosa cell tumor of the ovary. Am J Clin Pathol. 1986;85:402-5.

[13]. Khan N, Afroz N, Aquil B, Khan T, Ahmad I .Neoplastic and non-neoplastic ovarian masses. Diagnosis on cytology. J Cytol. 2009; 26:129-33.

[14]. Roy M, Bhattacharya A, Roy A, Sanyal S, Sangal MK, Dasgupta S, et al. Fine needle aspiration cytology of ovarian neoplasms. J Cytol 2003;20:31-5. 